\title{
Common errors and remedies in managing postpartum haemorrhage
}

\author{
Hennie Lombaard, MBChB(Pret), MMED(OetG)(PRET), FCOG(SA), \\ Senior Specialist ${ }^{a}{ }^{*}$, Robert C. Pattinson, MD, FCOG (SA), FRCOG, \\ Director, Clinical Head ${ }^{\mathrm{b}, \mathrm{c}}$ \\ ${ }^{a}$ Maternal and Fetal Medicine Unit, Department of Obstetrics and Gynaecology, University of Pretoria, South Africa \\ ${ }^{\mathrm{b}}$ MRC Maternal and Infant Health Care Strategies Research Unit, South Africa \\ ${ }^{\mathrm{c}}$ Obstetrics and Gynaecology Department, Kalafong, University of Pretoria, South Africa
}

Keywords:

postpartum haemorrhage

maternal morbidity and mortality

B-Lynch

internal iliac ligation

uterine tamponade

cell saver

\begin{abstract}
Postpartum haemorrhage (PPH) is a major contributor to maternal morbidity and mortality. By only examining mortality, the full extent of the problem is not revealed and also it is important to evaluate the avoidable factors. This will identify the areas that need attention. The common errors include not treating anaemia in pregnancy, not practicing active management of the third stage of labour, delay in recognition, substandard care and lack of skills. The remedies include the correct medical treatment of PPH and the use of uterine tamponade. Cell savers can help to reduce the need for transfusion and transfusion associated complications. There are new treatment modalities such as embolisation that can be of value in certain settings.
\end{abstract}

(c) 2009 Elsevier Ltd. All rights reserved.

Postpartum haemorrhage (PPH) is a major cause of maternal deaths around the world. ${ }^{1-3}$ The incidence of PPH is between 2 to $11 \%{ }^{4,5}$ According to the World Health Organisation (WHO), $10.5 \%$ of live births are complicated by PPH and in 2000 13,795,000 women suffered from PPH with 13,200 deaths. ${ }^{6}$ The second major cause of maternal deaths was sepsis causing 79,000 deaths. ${ }^{6}$ In the United Kingdom (UK), Waterstone and co-workers found the rate of PPH to be $6.7 / 1000$ deliveries. ${ }^{7,8}$ Low and co-workers found that $15 \%$ of deliveries in northern rural Honduras were complicated by $\mathrm{PPH} .{ }^{9}$ There is considerable variation in the PPH specific maternal mortality ratios between developed countries and

\footnotetext{
* Corresponding author. Maternal and Fetal Medicine, University of Pretoria, PO Box 2595 Montana Park, Pretoria, 0159 South Africa. Tel.:+27834078632; Fax:+27123296258.

E-mail address: hennie.lombaard@up.ac.za (H. Lombaard).
} 
developing countries. The rate for sub-Saharan Africa is 40 per 100,000 deliveries compared with the 1 per 100,000 deliveries in the UK and 8.9 per 100,000 in the United States of America. ${ }^{10,11}$ The last triennium report on maternal deaths from the Confidential Enquiries into Maternal and Child Health (CEMACH) in the UK reported 17 deaths due to postpartum haemorrhage. ${ }^{12,13}$

Looking only at deaths due to PPH can be misleading as it is the tip of a much larger iceberg. Some countries like Scotland have a national near miss audit and others like South Africa and Nigeria have institutional data. ${ }^{12,14-16}$ There is also near miss data from the capitol cities of the Brazilian states. ${ }^{17}$ Mantel and co-workers found that $55.8 \%$ of near misses in South Africa were due to PPH. In Canada, Baskett and co-workers found the rate to be $22 \%$, Waterstone in the UK found it to be $55.7 \%$, Brace in Scotland 50\% and Pural in West Africa 49.5\%. ${ }^{14,18}$ An alarming fact is that in both the Scottish data and the data from Nigeria there is a rise in morbidity due to PPH.

Despite PPH being a major cause of maternal near miss, it is not a common cause of maternal death in developed countries. There were 17 maternal deaths reported in the 2003-2005 CEMACH due to all forms of obstetric haemorrhage including uterine and vaginal trauma. ${ }^{19}$ In a case-controlled study on peripartum hysterectomy carried out by the UK Obstetric Surveillance System (UKOSS), 315 women were reported to have had a hysterectomy to control bleeding. Approximately 60 women undergo hysterectomy for haemorrhage for every woman that dies from the condition. ${ }^{20}$ It was estimated that $28 \%$ of the hysterectomies were associated with previous caesarean sections, often with a morbidly adherent placenta. Women who had had a previous caesarean section were three and a half times more likely to have a peripartum hysterectomy due to haemorrhage than women without a previous caesarean section. The main areas of substandard care in women who died were a failure to recognise concealed haemorrhage, mismanaging atonic uteri (substandard use of oxytocin and ergometrine) and poor identification and management of placenta percreta. ${ }^{19}$

In the Tshwane Region of Gauteng in South Africa, a maternal near miss audit has been ongoing since 1997. After the initial study ${ }^{21}$ the protocols for the major causes of maternal near miss were revised. The new protocols generally reduced the maternal near miss rate. ${ }^{22,23}$ However, the mortality index for PPH was unchanged from 5.2\% in 1997-8 to 6.2\% in 2002-6 (OR 1.18 95\% CI 0.25, 5.5). During 2002-6 there were 12 maternal deaths and 182 maternal near misses (Lombaard: Priorities in Perinatal Care Congress, Hartenbos 2007). The incidence of PPH was between 8-9\% (Mabenge, Lombaard: Priorities in Perinatal Care Congress, Hartenbos 2007) giving a case fatality rate of $0.18 \%$ for PPH. The lack of reduction in the mortality index was disappointing despite the introduction of the new protocols leading to a review of the protocol and identification of common errors. The common errors are given below and the protocol was adjusted to place more emphasis on achieving more immediate control of blood loss by using a balloon tamponade.

\section{Common errors}

Women who die from postpartum haemorrhage have more incidents of substandard care than near misses. The pattern of the errors is the same but the proportions of errors per case occurring less frequently in the maternal near miss group. This is illustrated in a comparison of maternal deaths and maternal near misses in the Pretoria Academic Complex between 2002 and 2006 where there were 2.25 errors per death as opposed to 0.61 errors per maternal near miss. (see Table 1 ).

The common errors relating to the health system are:

- Not directly preventing PPH

$\circ$ not using the active management of the third stage of labour

- Not reducing risk factors such as

o correcting anaemia antenatally

$\circ$ preventing prolonged labour

$\circ$ actively managing twin deliveries

- Not having sufficient skills available

$\circ$ recognising the severity of the bleeding

$\circ$ giving sufficient fluids in resuscitation 
Table 1

Comparison of avoidable factors in maternal deaths and maternal near misses.

\begin{tabular}{|c|c|c|c|c|}
\hline \multirow[t]{2}{*}{ Description } & \multicolumn{2}{|c|}{ Maternal death } & \multicolumn{2}{|c|}{ Maternal near miss } \\
\hline & $N$ & $\%$ & $N$ & $\%$ \\
\hline Initial assessment & 2 & 16.7 & 13 & 7.1 \\
\hline Problem with recognition / diagnosis & 3 & 25.0 & 23 & 12.6 \\
\hline Delay in referring patient & 0 & 0.0 & 11 & 6.0 \\
\hline Managed at inappropriate level & 0 & 0.0 & 1 & 0.5 \\
\hline Incorrect management (Incorrect diagnosis) & 2 & 16.7 & 10 & 5.5 \\
\hline Substandard management (Correct diagnosis) & 4 & 33.3 & 24 & 13.2 \\
\hline Not monitored / Infrequently monitored & 5 & 41.7 & 3 & 1.6 \\
\hline Prolonged abnormal monitoring without action & 5 & 41.7 & 2 & 1.1 \\
\hline Resuscitation & 6 & 50.0 & 24 & 13.2 \\
\hline Total & 12 & & 182 & \\
\hline Rate of errors & 2.25 & & 0.61 & \\
\hline
\end{tabular}

o delay in stopping the bleeding

o delay in progressing to the next step in management

o follow-up observations in the woman after initially stopping the bleeding

- Administrative and health care management problems

○ having appropriate medication and blood available

having sufficient facilities (ICU, 24 hour theatre availability)

o transport problems

Not recognising risk factors for PPH such as antenatal anaemia, prolonged labour and twin pregnancies are a common fault.

Most deaths due to PPH occur at home or at lower levels of care. ${ }^{24}$ Deaths at home often relate to lack of available transport to move the woman to an appropriate centre of care. Deaths at the lower levels of care are frequently associated with not recognising the severity of the bleeding, lack of transport, inadequate management skills and lack of drugs and resuscitation fluids. ${ }^{25}$

\section{Prevention}

An important part of PPH prevention is active management of the third stage of labour and it has been shown to be an effective method of reducing the risk of PPH (Relative risk [RR] of 0.38 95\% CI [Confidence Interval] 0.32-0.46) ${ }^{26}$ Oxytocin is the drug of choice for the management of the third stage of labour to reduce PPH (RR $0.5395 \%$ CI 0.39-0.65). ${ }^{27}$ The combination of ergometrineoxytocin had no statistically significant reduction in blood loss between 500 and $1000 \mathrm{ml}$ but had significantly more side effects. ${ }^{28}$ Prophylactic ergot preparations in the third stage of labour reduce the risk of PPH significantly (RR $0.3895 \% \mathrm{CI} 0.21-0.69$ ) but there was an increase in vomiting (RR $11.8195 \%$ CI 1.78-78.28), raised blood pressure (RR 2.60 95\% CI 1.03-6.57) and pain (RR 2.53 95\% CI 1.34-4.78) compared with placebo. ${ }^{29}$ Oral or sublingual misoprostol was effective in preventing PPH (RR of $0.6695 \% 0.45$ to 0.98 ) compared with placebo and for reducing the need for blood transfusion (RR $0.3195 \%$ CI 0.10 to 0.94 ). ${ }^{30}$ Misoprostol compared with injectable uterotonics such as oxytocin was associated with fewer blood transfusions (RR $0.8195 \%$ CI 0.64 to 1.02 ) but with a higher risk of severe PPH (RR 1.32 95\% CI 1.61-1.51). ${ }^{30}$

If all injectable and oral uterotonic drugs are available the WHO recommends ${ }^{31}$ :

- skilled attendants should offer oxytocin to all women for the prevention of PPH in preference to ergometrine/methylergometrine

- oxytocin should be used in preference to oral misoprostol

- oxytocin should be used in preference to carboprost/sulprostone 
If oxytocin is not available:

- skilled attendants should offer ergometerine/methylergometrine or the fixed drug combination of oxytocin and ergometrine to women without hypertension or heart disease for prevention of PPH.

This chapter will deal with the techniques of management and skills training for preventing PPH.

\section{Remedies}

The remedies include the following:

- medical therapy including oxytocin, ergometrine and misoprostol

- balloon catheter tamponade of the uterus

- B-Lynch procedure

- systemic devascularisation

- internal iliac ligation

- the use of cell saver

- embolisation

- fire drills, protocols and skills training.

Oxytocin, ergometrine and misoprostol

Oxytocin can be used as first line therapy. ${ }^{2,5,32,33}$ It has a short half life of three minutes but care should be taken with the route of administration. The intra-muscular route has a delayed effect of up to 7 minutes but the duration of the effect is almost 1 hour. ${ }^{32}$ The intravenous route of administration gives almost immediate effect but is associated with a shorter duration lasting 30 minutes. ${ }^{32}$ It is safer to administer oxytocin intravenously as 20 Units diluted in 500 to a $1000 \mathrm{ml}$ fluids and administered at a rate of $250 \mathrm{ml} / \mathrm{hr}$ but should always be titrated against effect. ${ }^{2,5,32}$ A risk of oxytocin administration is that it has $5 \%$ antidiuretic effect of vasopressin and therefore care should be taken when administrating large volumes of fluid and oxytocin. ${ }^{2,32}$

Ergometrine causes uterine contraction via the $\alpha$-adrenergic receptors. ${ }^{18}$ The effect lasts for up to 3 hours but the onset takes up to 5 minutes. ${ }^{2,18}$ The combination of oxytocin and ergometrine gives a rapid onset of action and a prolonged effect. ${ }^{32}$ The side effects of ergometrine are nausea, vomiting and dizziness and are more common after intravenous injection. Another serious complication is the development of hypertension after administration due to vasoconstriction. ${ }^{32}$

Misoprostol, a synthetic prostaglandin E1 analogue, has been used for the treatment of postpartum haemorrhage. ${ }^{32,34}$ A Cochrane review of the treatment of postpartum haemorrhage found that the combination of ergometrine and oxytocin was as good as misoprostol. ${ }^{26}$ It was found from placebo controlled trials with dosages between 600 and 1000 mcg that there were no significant reductions in maternal mortality (RR 7.24 95\% CI 0.38 - 138.6), hysterectomy (RR 1.24, 95\% CI 0.04-40.78) and the additional use of uterotonics (RR $0.9895 \% \mathrm{CI} 0.78-1.24$ ). The same was found for blood transfusion and evacuation. ${ }^{26}$ Hofmeyr and co-workers also evaluated the effect of misoprostol on maternal mortality. Forty-seven trials which included 40,000 patients were evaluated. They found that women receiving misoprostol had a relative risk of death of $2.095 \%$ (CI $0.68-5.83) .{ }^{34}$ They also comment that a limitation of the review was that there were only eight maternal deaths that gave wide confidence intervals that were non-significant. This was not a prospective trial with only post-hoc analysis. ${ }^{34}$ Also, the correct dosage of misoprostol is still unknown. Breathnach and Geary reported the success of studies with $800 \mu$ g rectally that resulted in a longer onset of action and lower peak levels. ${ }^{32}$ Hofmeyr and Gülmezoglu favour a dosage of 400 to $600 \mu \mathrm{g}$. From their meta-analysis they found no difference in benefit between the two dosages. ${ }^{34}$ They excluded studies with rectal administration because of uncertainty about the absorption. ${ }^{34}$ The oral dosage of $800 \mu \mathrm{g}$ was associated with life threatening pyrexia. ${ }^{34}$ To conclude, for the treatment of PPH an oxytocin-ergometrine combination is the recommended first line treatment. Misoprostol has a place, but at the lower oral dosage that is as effective as rectal administration but with fewer side effects. 
Balloon catheter tamponade of the uterus

Uterine packing with gauze swabs has been used with some success but because of concerns of concealed bleeding is used infrequently. ${ }^{2,5,35}$ The Sengstaken-Blakemore balloon with the stomach end cut off, the Rush hydrostatic balloon or the Bakri balloon have all been used with success. ${ }^{5,36}$ All these methods work with a success rate of $84.0 \%$ based on a study by Doumouchtsis and co-workers who evaluated a 162 case series. ${ }^{8}$ In a prospective audit the same authors found that the SengstakenBlakemore balloon was successful in $80 \%$ of cases in stopping bleeding once medical therapy had failed. ${ }^{37}$ The one disadvantage of these balloons is their price. The major advantage is that they are easy to insert and there is no need for anaesthesia. The balloon tamponade can also be used as a diagnostic test to see whether a patient with PPH requires further surgery or not. ${ }^{35,36}$ If the bleeding is stopped after placement of the balloon intensive monitoring is indicated but no further surgery indicated. Ideally the patient should be in theatre in the Lloyd Davis or lithotomy position with theatre and anaesthetic staff available. ${ }^{36}$ The balloon is placed after a manual examination of the uterine cavity to exclude retained products and trauma, making sure that the balloon is inserted beyond the cervical opening and the balloon is then filled with the required amount of fluid. ${ }^{36}$ A vaginal pack is placed to prevent the balloon being expelled. The balloon is usually removed after 24 to 48 hours. ${ }^{5}$ As an alternative to these expensive balloons a Foleys catheter with a condom tied with silk over the tip can be used and placed in the same way. This technique is used in the Life Saving Skills from the Royal College and also in the Essential Steps in Managing Obstetrics Emergencies (ESMOE) course used in South Africa. Personal experience with the use of a Foley catheter and a condom used in patients with postpartum haemorrhage due to disseminated intravascular coagulopathy stopped the bleeding long enough to allow medical therapy to succeed.

After a balloon is placed the following should be preformed provided the bleeding has stopped ${ }^{36}$ :

- admit to a High Care Unit

- monitor vital signs, input/output, uterine fundal height and vaginal blood loss

- administer broad spectrum antibiotics

- give continuous oxytocin infusion over 12 to 24 hours

- gradual deflating of the balloon over time.

Although Danso and Reginald state that it should be placed in theatre ${ }^{36}$, it can also be used in low income countries in level 1 health care facilities by the midwifes as an emergency measure to allow for the patient to be transferred to the next level of care.

\section{Lynch procedure}

The B-Lynch procedure is a compression brace suture that gives vertical compression on the vascular system of the uterus ${ }^{38}$ and is best for cases of uterine atony not responding to medical therapy. ${ }^{2}$ The success of the B-Lynch procedure according to Mr B-Lynch's personal database has 1300 successful cases and 19 failures. ${ }^{38}$ According to Doumouchtsis and co-workers the success rate is $91.7 \%$ (95\% CI 84.9\% - 95.5\%) from 108 published case reports. ${ }^{8}$

The technique of the B-Lynch is as follows $2,38,39$

The patient should to be in the Lloyd Davis position and a laparotomy performed. A lower transverse incision in the uterus is made and the cavity inspected for retained products and partial tears or rupture. The bladder peritoneum needs to be reflected below the cervix. Bimanual compression is applied to the uterus with the surgeon's outstretched hand behind the length of the uterus and the other hand just below the bladder reflection. If the bleeding stops the surgeon can proceed. The assistant takes over the bimanual pressure. The corner sutures in the uterine incision must be placed before the brace suture is started. The best suture is the monocryl no. 1 suture on a $90 \mathrm{~mm}$ curved needle. The needle is passed full thickness through the anterior uterine wall $3 \mathrm{~cm}$ below the incision and $3 \mathrm{~cm}$ medial from the lateral uterine wall. The suture is taken inside the cavity and exits the 
anterior uterine wall $3 \mathrm{~cm}$ above the incision and $4 \mathrm{~cm}$ medial of the lateral border. The suture crosses over the fundus about $4 \mathrm{~cm}$ from the cornu and should be almost vertical. The suture goes down vertically over the posterior border of the uterus and enters at the level of the junction of the uterus and the uterosacral ligaments and about the same level of the lower segment transverse incision. The suture is passed full thickness through the posterior wall into the cavity and crosses over horizontally and then exits the cavity through the posterior uterine wall. The process is repeated in reverse order. The suture is milked through until maximum tension is reached and it is then tied while full compression is still applied by the assistant.

Documented complications include the following ${ }^{2,8}$ :

- erosion through the uterine wall

- uterine necrosis

- infection

\section{Systemic devascularisation and internal iliac ligation}

AbdRabbo first described a stepwise devascularisation for severe postpartum haemorrhage in 1994. ${ }^{40}$ Since then Doumouchtsis evaluated 501 cases and found the success rate to be $84.6 \%{ }^{8}$

\section{Technique for systemic devascularisation ${ }^{2}$}

The patient should be placed in the Lloyd David position in order to evaluate any change in vaginal bleeding as the procedure is performed. The suture is placed full thickness through the myometrium $2 \mathrm{~cm}$ medial from the broad ligament at the level of the internal os and then passed through an avascular space through the broad ligament from posterior to anterior and tied to ligate the uterine artery. The suture material is an absorbable number 1 on a large curved needle. If the patient is still bleeding the other side should also be ligated.

If the patient continues to bleed a suture should be placed near the insertion of the utero-ovarian ligament to ligate the ovarian arteries. This should be repeated on the opposite side if the patient still bleeds. If this is not successful internal iliac ligation should be considered.

\section{Technique of internal iliac ligation ${ }^{2,41}$}

The skin should be opened through either a midline or a wide transverse incision but adequate exposure is crucial. The peritoneum is opened by pulling the uterus forward and cutting the posterior part of the broad ligament just below the round ligament at the junction of the medial and middle thirds and extending the incision proximally for $10 \mathrm{~cm}$. The ureter should be on the medial part of the peritoneum and should be dissected free for better visualisation. The peritoneum can also be incised directly over the bifurcation of the iliac arteries but care should be taken not to damage the underlying blood vessels. The areolar tissue should be dissected apart by blunt dissection. Identify the bifurcation and both the external and internal iliac vessels. The internal iliac vessel is at right angles at the bifurcation and dives into the pelvis. Dissect open the tissue above the internal iliac artery until the bifurcation of the anterior and posterior divisions is seen. Under good vision the internal iliac artery should be separated from the vein. Care should be taken not to injure the vein. Once the two are separated a blunt tipped instrument like a Mixter or other right-angled forceps is gently introduced between them from medial to lateral. The internal iliac artery anterior division is tied off twice 0.5 to $1 \mathrm{~cm}$ below the bifurcation with the ties $0.5 \mathrm{~cm}$ apart. It is important to check the foot pulse to be sure that the external iliac vessel was not ligated.

\section{Cell saver}

Cell saving techniques and autologous transfusion have been used in obstetrics for some time., , $^{4}$ There are two major concerns regarding the use of cell-saved blood. The first is that a Rhesus negative mother with a Rhesus positive foetus may be immunised during the transfusion. It is therefore important to do the Kliehauer test to determine the amount of foetal blood in the maternal circulation 
and then to administer anti-D within 72 hours. ${ }^{42}$ Since the washed cells are platelet depleted the coagulation system should be checked. ${ }^{42}$ There is also the concern of amniotic fluid embolism when blood contaminated with amniotic fluid is sucked up. ${ }^{5,42}$ To prevent this possible complication there are several steps that can be taken ${ }^{42}$ :

- suck up amniotic fluid with a separate suction device

- use a leucocyte depletion filter.

Several studies have shown that most of the known substances that are associated with amniotic fluid embolism are cleared in this way. ${ }^{42}$

Important points in the technique of cell saving include ${ }^{42}$ :

- sucking up pools of blood with a large bore cannula to prevent red cell damage

- rinsing blood soaked swabs gently in normal saline and salvaging the cells

- keeping the suction pressure as low as possible

- careful monitoring of the patient should take place the first 24 hours after transfusion, including monitoring of the coagulation system.

\section{Embolisation}

Pelvic embolisation is a treatment option for PPH in selected cases. ${ }^{5,43}$ The success rate of embolisation based on a review of published case series by Doumouchsis is $90.7 \%{ }^{8,43}$ Embolisation can only be performed when the mother is haemodynamically stable. ${ }^{5,43}$ It is therefore better to identify women at risk of PPH, for example placenta accreta and to perform prophylactic procedures. ${ }^{11,43}$ In these cases a balloon is placed in the blood vessels and only inflated after delivery of the foetus. This technique is associated with preserved fertility. ${ }^{43}$ The use of uterine artery embolisation is indicated after the initial resuscitation with medical therapy has failed. ${ }^{43}$

Expected complications associated with embolisation include the following ${ }^{44}$ :

- haematomas at the puncture site

- vascular injuries

- allergic reactions

- uterine infarction and necrosis

- infection

- coagulopathy

- acute intra-arterial thrombosis or ischemia of the lower limb.

Fire dills, protocols and skills training

Skills training in obstetrics emergencies has been shown to improve neonatal outcome in cases of shoulder dystocia and hypoxic -ischemic encephalopathy. ${ }^{45,46}$ The adherence to a strict protocol in management of women with severe hypertensive disease in pregnancy has also shown to improve maternal outcome. ${ }^{22}$ There are some courses focusing on skills training in obstetric practice such as: the Managing Obstetrics Emergencies and Trauma (MOET) developed in the United Kingdom and the ESMOE course in South Africa. The MOET course has shown to improve knowledge in obstetric emergencies with significant improvement in the scenario management of postpartum haemorrhage. ${ }^{47}$ During the pilot study for the ESMOE course there was a significant improvement in the skills of the candidates (unpublished data). Simulation training helps with the transfer of knowledge but also in the training of emergency drills. ${ }^{48}$ The further advantages of scenario drills are that they serve as a basis for further improvement of skills. ${ }^{49}$ A concern of conducting drills in busy units is that they may take people from clinical service delivery but the counter argument is that the fire drills should be done 
in the clinical setting where the problem occurs. ${ }^{49}$ When fire drills are performed there should be an observer with a checklist to be able to give adequate feedback and monitor the improvement.

To improve the quality of care there should be formal teaching in fire drills, skills and scenarios. ${ }^{50}$ From an educational point it is important to understand that these three teaching styles differ in their aims. The aim of skills is to ensure the correct technique is used, of fire drills is to test the system and a scenario is to apply and practise clinical care. ${ }^{50}$

All of the maternal death reports indicate that there must be written protocols available in labour wards for the management of PPH. ${ }^{12,24}$ In New South Wales the Department of Health created an evidence based framework for the management of $\mathrm{PPH}^{51} \mathrm{~A}$ review of the implementation process found that certain issues like monitoring should be standard throughout all the health care institutions but in other areas it should be tailored toward the specific health care institution. ${ }^{51}$

\section{Conclusion}

PPH remains a major contributor to maternal morbidity and mortality. $6,12,14,52,53$ It is clear that doing further research will contribute to the understanding of the possible causes and the best treatment modalities. ${ }^{52,53}$ For the comparison of research data there needs to be a standard definition or set of criteria for defining maternal near misses. Unfortunately, avoidable factors are still a main contributor to morbidity and mortality. In South Africa not preventing postpartum haemorrhage and lack of skills were the most common avoidable factors. It is important as part of the fight to reduce morbidity and mortality that anaemia should be treated early in pregnancy and that active management of the third stage of labour should be practiced at all deliveries. All health care providers should have sufficient skills to manage postpartum haemorrhage. Health care administrators should help to make sure that health care facilities have the correct staffing norms and equipment to deal with this problem.

\section{Practice points}

- Treat anaemia early in pregnancy

- Active management of third stage of labour

- Lower dosage used of misoprostol, not more than $600 \mu \mathrm{g}$

- Skills training of the people involved in maternity care

\section{Research agenda}

- The correct dose and route of administration of misoprostol for the treatment of PPH

- The place of arterial embolization in the management of PPH

- The outcome of skills training and fire drills on maternal morbidity due to PPH

\section{Conflict of interest}

None declared.

\section{Acknowledgements}

Thank you to Prof AP Macdonald who helped with the editing of the paper. 


\section{References}

1. Jansen AJG, Van Rhenen DJ, Steegers EAP et al. Postpartum hemorrhage and transfusion of blood and blood components. Obstet Gynecol Surv 2005; 60: 663-671.

2. Oyelese Y, Scorza WE, Mastrolia R et al. Postpartum hemorrhage. Obstet Gynecol Clin North Am 2007; 34: 421-441.

3. Kominiarek MA, Kilpatrick SJ. Postpartum hemorrhage: A recurring pregnancy complication. Semin Perinatol 31: 159-166.

4. Sobieszczyk S, Breborowicz GH, Platicanov V et al. Recombinant factor VIIa in the management of post partum bleeds: an audit of clinical use. Acta Obstet Gynecol 2006; 85: 1239-1247.

*5. Mercier FJ \& Van de Velde M. Major obstetric hemorrhage. Anesthesiol Clin 2008; 26: 53-66.

6. Cameron MJ \& Robson SC. Vital statistics: an overview. In B-Lynch C, Keith LG, Lalonde AB \& Karoshi M (eds.). A Textbook of Postpartum Hemorrhage. A comprehensive guide to evaluation, management and surgical intervention. 1st edn. Sapiens Publishing, 2006, pp. 17-34.

*7. Mousa HA, Cording V \& Alfirevic Z. Risk factors and interventions associated with major primary post partum hemorrhage unresponsive to first-line conventional therapy. Acta Obstet Gynecol 2008; 87: 652-661.

*8. Doumouchtsis SK, Papageorghiou AT \& Arulkumaran S. Systemic review of conservative management of postpartum hemorrhage: what to do when medical therapy fails. Obstet Gynecol Surv 2007; 62: 540-547.

9. Low LK, Bailey JM, Sacks E et al. Postpartum hemorrhage prevention: a case study in northern rural Honduras. J Midwifey Womens Health 2008; 53: e1-e6. Available from: www.jmwh.org.

10. Hofmeyr J, Walraven G, Gülmezoglu AM et al. Misoprostol to treat postpartum haemorrhage: a systematic review. $\mathrm{Br} J$ Obstet Gynecol 2005; 112: 547-553.

11. You WB \& Zahn CM. Postpartum hemorrhage: Abnormally adherent placenta, uterine inversion and puerperal hematomas. Clin Obstet Gynecol 2006; 49: 184-197.

12. Confidential enquiry into Maternal and Child Health. Saving mothers lives: reviewing maternal deaths to make motherhood safer - 2003-2005. Executive summary and key recommendations. London RCOG Press, 2007. Available from: www.cemach. org.uk.

13. Wise A \& Clark V. Strategies to manage major Obstetric haemorrhage. Curr Opin Anaesthesiol 2008; 21: 281-287.

14. Brace V, Penney G \& Hall M. Quantifyiyng severe maternal morbidity: a Scottish population study. Br J Obstet Gynecol 2004; 111: 481-484.

15. Mantel GD, Buchmann E, Rees $\mathrm{H}$ et al. Severe acute maternal morbidity: a pilot study of the definition for a nearmiss. $\mathrm{Br} J$ Obstet Gynecol 1998; 105: 985-990.

16. Oladapo OT, Ariba AJ \& Odusoga OL. Changing patterns of emergency obstetric care at a Nigerian University hospital. Int J Gynaecol Obstet 2007; 98: 278-284.

17. Sousa MH, Cecatti JG, Hardy EE et al. Severe maternal morbidity (near miss) as a sentinel event of maternal death. An attempt to use routine data for surveillance. Reprod Health 2008; 5. Available from: www.reproductive-health-journal. com/content $/ 5 / 1 / 6$.

18. Vais A \& Bewley S. Severe acute maternal morbidity. In B-Lynch C, Keith LG, Lalonde AB \& Karoshi M (eds.). A Textbook of postpartum hemorrhage. A comprehensive guide to evaluation, management and surgical intervention. 1st edn. Sapiens Publishing, 2006, pp. 339-352.

19. Listom W. Haemorrhage. In: Confidential enquiry into maternal and child health. Saving mothers lives: Reviewing maternal deaths to make motherhood safer - 2003-2005. Executive summary and key recommendations. London RCOG Press, 2007. Available from: www.cemach.org.uk.

20. Knight M, Kurinczuk JJ, Spark P et al. United Kingdom Obstetric Surveillance System (UKOSS) Annual Report. Oxford: National Perinatal Epidemiology Unit, 2007.

21. Pattinson RC, Buchmann EJ, Mantel G et al. Can enquiries into maternal morbidity act as a surrogate for maternal death enquiries? Br J Obstet Gynecol 2003; 110: 889-893.

22. Lombaard HA, Pattinson RC, Backer F et al. Evaluation of a strict protocol approach in managing women with severe disease due to hypertension in pregnancy: a before and after study. Reprod Health 2005; 30: 1-7.

23. Pattinson RC, Macdonald AP, Backer F et al. The effect of audit on critically ill women. Clin Gov Int J 2006; 11(4): $278-288$. MPS Special Issue - Making and Sustaining a Difference.

24. Fawcus S, Mbombo N-F, Hofmeyr J. Obstetric haemorrhage. In: Pattinson RC (ed.) Saving mothers 2005-2007: Fourth report on Confidential enquiries into maternal deaths in South Africa, Goverment Prinyter Pretoria, in press.

25. Prendiville WJ, Elbourne D \& McDonald S. Active versus expectant management in the third stage of labour. In Hofmeyr GJ, Neilson JP, Alfirevic Z, Crowther CA, Duley L, Gülmezoglu M, Gyte GML \& Hodnett ED (eds.). A Cochrane pocketbook pregnancy and childbirth. John Wiley and Sons, 2007, pp. 268-269.

26. Mousa HA \& Alfirevic Z. Treatment for primary postpartum haemorrhage. Cochrane Database Syst Rev 2007; (Issue 1). doi: 10.1002/14651858.CD003249.pub2. Art. No.: CD003249.

27. Cotter A, Ness A \& Tolosa J. Prophylactic oxytocin for the third stage of labour. Cochrane Database Syst Rev 2001; (Issue 4). doi:10.1002/14651858.CD001808. Art. No.: CD001808.

28. McDonald SJ, Abbott JM \& Higgins SP. Prophylactic ergometrine-oxytocin versus oxytocin for the third stage of labour. Cochrane Database Syst Rev 2004; (Issue 1). doi:10.1002/14651858.CD000201.pub2. Art. No.: CD000201.

29. Liabsuetrakul T, Choobun T, Peeyananjarassri K et al. Prophylactic use of ergot alkaloids in the third stage of labour. Cochrane Database Syst Rev 2007; (Issue 2). doi:10.1002/14651858. CD005456.pub2. Art. No.: CD005456.

30. Gülmezoglu AM, Forna F, Villar J et al. Prostaglandins for preventing postpartum haemorrhage. Cochrane Database Syst Rev 2007; (Issue 3). doi:10.1002/14651858. CD000494.pub3. Art. No.: CD000494.

31. WHO recommendations for the prevention of postpartum haemorrhage. WHO Press, 2007.

32. Breathnach F \& Geary M. Standard medical therapy. In B-Lynch C, Keith LG, Lalonde AB \& Karoshi M (eds.). A textbook of postpartum hemorrhage. A comprehensive guide to evaluation, management and surgical intervention. 1 st edn. Sapiens Publishing, 2006, pp. 256-262.

33. Walvaren G, Wanyonyi S \& Stones W. Management of post-partum hemorrhage in low income countries. Best Pract Res Clin Obstet Gynecol 2008; 22: 1013-1023. 
*34. Hofmeyr GJ \& Gülmezoglu AM. Misoprostol for the prevention and treatment of post partum haemorrhage. Best Pract Res Clin Obstet Gynecol 2008; 22: 1025-1041.

35. Ferrazzani S, Guariglia L \& Dell'Aquila C. The balloon internal uterine tamponade as a diagnostic test. In B-Lynch C, Keith LG, Lalonde AB \& Karoshi M (eds.). A Textbook of postpartum hemorrhage. A comprehensive guide to evaluation, management and surgical intervention. 1st edn. Sapiens Publishing, 2006, pp. 268-276.

*36. Danso D \& Reginaldd PW. Internal uterine tamponade. In B-Lynch C, Keith LG, Lalonde AB \& Karoshi M (eds.). A Textbook of postpartum hemorrhage. A comprehensive guide to evaluation, management and surgical intervention. 1st edn. Sapiens Publishing, 2006, pp. 263-267.

37. Doumouchtsis SK, Papageorghiou AT, Vernier C et al. Management of postpartum hemorrhage by uterine balloon tamponade: Prospective evaluation of effectiveness. Acta Obstet Gynecol Scand 2008; 87: 849-855.

*38. B-Lynch C. Conservative surgical management. In B-Lynch C, Keith LG, Lalonde AB \& Karoshi M (eds.). A Textbook of postpartum hemorrhage. A comprehensive guide to evaluation, management and surgical intervention. 1st edn. Sapiens Publishing, 2006, pp. 287-298.

39. Habeck D, Kulas T, Bobic-Vukovic M et al. Successful of the B-Lynch compression suture in the management of massive postpartum hemorrhage: case reports and review. Arch Gynecol Obstet 2006; 273: 307-309.

40. AbdRabbo SA. Stepwise uterine devascularization:a novel technique for management of uncontrolled postpartum hemorrhage with preservation of the uterus. Am J Obstet Gynecol 1994; 171: 694-700.

*41. B-Lynch C, Keith LG \& Campbell WB. Internal iliac (hypogastric) artery ligation. In B-Lynch C, Keith LG, Lalonde AB \& Karoshi M (eds.). A Textbook of postpartum hemorrhage. A comprehensive guide to evaluation, management and surgical intervention. 1st edn. Sapiens Publishing, 2006, pp. 299-307.

*42. Catlling S \& Thomas D. Intraoperative autologous blood transfusion. In B-Lynch C, Keith LG, Lalonde AB \& Karoshi M (eds.). A Textbook of postpartum hemorrhage. A comprehensive guide to evaluation, management and surgical intervention. 1 st edn. Sapiens Publishing, 2006, pp. 421-426.

*43. Winogard RH. Uterine artery embolization for postpartum hemorrhage. Best Pract Res Clin Obstet Gynecol 2008; 22: 1119-1132.

44. Choji K \& Shmizu T. Embolization. In B-Lynch C, Keith LG, Lalonde AB \& Karoshi M (eds.). A Textbook of postpartum hemorrhage. A comprehensive guide to evaluation, management and surgical intervention. 1st edn. Sapiens Publishing, 2006, pp. 299-307.

45. Draycott T, Sibanda T, Owen L et al. Does training in obstetric emergencies improve neonatal outcome? Br J Obstet Gynecol 2006; 113: 177-182.

46. Draycott TJ, Crofts JF, Wilson LV et al. Improving neonatal outcome through practical shoulder dystocia training. Obstet Gynecol 2008; 112: 14-20.

47. Johanson RB, Menon V, Burns E et al. Managing Obstetrics Emergencies and Trauma (MOET) structured skills training in Armenia, utilizing models and reality based scenarios. BMC Med Educ 2002; 2: 1-5, http://www.biomedcentral. com1472-6920/2/5.

48. Johannson H, Ayida G \& Sadler C. Faking it? Simulation in the training of obstetricians and gynaecologists. Curr Opin Obstet Gynecol 2005; 17: 557-561.

49. Anderson ER, Black R \& Brockelhurst P. Acute obstetric emergency drill in England and Wales: a survey of practice. $\mathrm{Br} J$ Obstet Gynecol 2005; 112: 372-375.

50. Tipples M \& Paterson Brown S. Labor ward drills. In B-Lynch C, Keith LG, Lalonde AB \& Karoshi M (eds.). A textbook of postpartum hemorrhage. A comprehensive guide to evaluation, management and surgical intervention. 1st edn. Sapiens Publishing, 2006, pp. 127-135.

*51. Cameron CA, Robberts CL, Bell J et al. Getting an evidence-based post-partum haemorrhage protocol into practice. Aus N Z J Obstet Gynecol 2007; 47: 169-175.

52. Cecatti JG, Souza JP, Parpinelli MA et al. Research on severe maternal morbidities and near-misses in Brazil: What we have learned. Reprod Health Matters 2007; 15: 125-133.

53. Souza JP, Cecatti JG, Parpinelli MA et al. Appropriate criteria for identification of near-miss maternal morbidity in tertiary care facilities: A cross sectional study. BMC Preg Childbirth 2007; 20: 1-8. 